\title{
Indicadores sociais sobre pessoas com deficiência intelectual: ensaio interseccional com vistas a políticas de educação
}

\author{
Ingrid Anelise Lopes ${ }^{1}$ \\ ORCID: 0000-0003-1690-5587 \\ Roseli Kubo Gonzalez² \\ ORCID: 0000-0002-0639-3541 \\ Rosângela Gavioli Prieto ${ }^{1}$ \\ ORCID: 0000-0003-4013-1163
}

\section{Resumo}

Com o objetivo de analisar intersecções entre indicadores sociais relacionados às pessoas classificadas na categoria deficiência intelectual (DI) no Brasil e suas implicações para as políticas educacionais, neste artigo apresentamos a caracterização dessa população a partir da extração de dados do Censo Demográfico de 2010, aplicando as recomendações do Grupo de Washington para a definição do quantitativo de pessoas com deficiência no país. Da análise de perspectiva interseccional, conclui-se que, em comparação com as demais categorias de deficiência, DI é a que mais sofre desvantagens nos indicadores de acesso ao trabalho (ocupação), rendimento nominal mensal e alfabetização. Além disso, os resultados quanto à categoria sexo mostram este como um eixo de subordinação, uma vez que o feminino apresenta menos acesso aos direitos sociais abordados neste estudo. Em relação à identificação racial das pessoas com DI no país, esta parece influenciar a classificação de sujeitos nessa categoria de deficiência, uma vez que é composta majoritariamente por homens negros. Contudo os dados não nos permitiram articular o eixo raça com os demais, indicando a emergente necessidade de produzir e divulgar informações que permitam análise e apreensão de como diferentes eixos de subordinação afetam a vida das pessoas com DI no Brasil e o que indicam para a implementação das políticas educacionais, como um vetor no enfrentamento de desigualdades que marcam singularmente a situação das pessoas com DI quando comparadas à população geral e, também, a outras categorias de deficiência.

\section{Palavras-chave}

Deficiência intelectual - Indicadores sociais - Interseccionalidade.

1- Universidade de São Paulo, São Paulo, SP, Brasil. Contatos: ingrid.anelise@ifsp.edu.br; rosangel@usp.br

2- Centro Universitário Senac, São Paulo, SP, Brasil. Contato: rkugon@yahoo.com.br 


\title{
Social indicators on people with intellectual disabilities: intersectional essay with a view to education policies
}

\begin{abstract}
With the aim of analyzing intersections between social indicators related to people classified in the intellectual disability (ID) category in Brazil and their implications for educational policies, in this article we present the characterization of this population based on the extraction of data from the 2010 Demographic Census, applying the recommendations of the Washington Group for defining the number of people with disabilities in the country. From the analysis of an intersectional perspective, it is concluded that, compared to the other categories of disability, ID is the one that suffers the most disadvantages in the indicators of access to work (occupation), monthly nominal income and literacy. In addition, the results regarding the gender category show this as an axis of subordination, since the female has less access to social rights addressed in this study. Regarding the racial identification of people with ID in the country, this seems to influence the classification of individuals in this category of disability, since it is mostly composed of black men. However, the data did not allow us to articulate the race axis with the others, indicating the emerging need to produce and disseminate information that allows analysis and understanding of how different subordination axes affect the lives of people with ID in Brazil and what they indicate for implementation of educational policies, as a vector in the confrontation of inequalities that uniquely mark the situation of people with ID when compared to the general population and also to other categories of disability.
\end{abstract}

\section{Keywords}

Intellectual disability - Social indicators - Intersectionality.

\section{Introdução}

Neste artigo temos como objetivo analisar intersecções entre indicadores sociais relacionados às pessoas classificadas na categoria deficiência intelectual (DI) no Brasil e suas implicações no concernente às políticas educacionais. Consideramos como base das análises os dados mais recentes do Censo Demográfico do Instituto Brasileiro de Geografia e Estatística ${ }^{3}$ (IBGE), a edição de 2010, doravante Censo 2010. Tomamos como referência a contribuição de estudos interseccionais (CRENSHAW, 2002; CARNEIRO, 2011; DAVIS, 2016) para a compreensão mais acurada das articulações entre alguns eixos de subordinação (CRENSHAW, 2002), comumente convertidos em desigualdades, a exemplo

3- "O IBGE [...] se constitui no principal provedor de dados e informações do País, que atendem às necessidades dos mais diversos segmentos da sociedade civil, bem como dos órgãos das esferas governamentais federal, estadual e municipal”. Disponível em: https://bit.ly/2yYACCh. Acesso em: 19 nov. 2019. 
de sexo e raça, atributos que também constituem as condições de vida das pessoas com deficiência (GOES, 2014).

Historicamente, a compreensão sobre as pessoas com algum tipo de deficiência tem sido marcada por sua diferenciação em relação às não classificadas nessa categoria, desconsiderando que a constituição de todo ser humano é intrínseca às suas condições concretas de vida. Com isso, comumente, as ideias sobre essas pessoas são sustentadas por uma concepção homogeneizadora, ou seja, pela negação da diversidade entre os indivíduos, configurada "[...] na histórica distinção categorial das deficiências que os entendia como um conjunto diferenciado de seres humanos quanto aos seus processos constitutivos, mas homogêneo dentro da categoria deficiência” (GOES, 2014, p. 13). Isso implica um predomínio de produções no campo das políticas públicas sobre o tema, apontando a deficiência sem considerar outros aspectos da constituição humana (GONZALEZ, 2013).

Apesar dessa lacuna, o estudo de Meyer e Patton (2001) aponta a influência da questão racial sobre identificação e encaminhamento de estudantes para serviços de educação especial nos Estados Unidos da América (EUA), uma vez que os alunos afroamericanos são mais percebidos como tendo uma deficiência e pouco identificados como possuindo altas habilidades/superdotação no país. Ademais, a maioria dos estudantes classificados com DI nos EUA é negra, do sexo masculino, conforme ampla revisão de literatura realizada por Gonzalez (2013).

Pesquisas brasileiras (MENDES; LOURENÇO, 2009; GONZALEZ, 2013; PEREIRA, 2016) acenam na mesma direção ao apreender que, no Brasil, os serviços de educação especial são, em geral, ocupados por $2 / 3$ de meninos e $1 / 3$ de meninas, o que pode ser reflexo do viés de gênero sobre a percepção da escola na identificação desse alunado.

Por essa razão, os desafios da política de educação especial (BRASIL, 2008) não residem apenas nas especificidades educacionais de cada estudante em função da categoria de deficiência que o enquadra, mas também na compreensão de como múltiplos aspectos de sua vida podem influenciar sua escolarização. Com isso, concordamos com Goes (2014) que a nomeação deficiência pode não ter permitido o entendimento de que esses indivíduos não são somente pessoas com deficiência,

[...] antes são homens, mulheres, pobres, ricos, negros, brancos, etc. Por essa razão, o desafio da educação inclusiva não reside somente na perspectiva da generalidade dos alunos, mas também nas modificações que essa experiência atribui a todos os indivíduos no espaço social. (GOES, 2014, p. 13).

Considerando esse panorama, apoiamo-nos em estudos sobre interseccionalidade para a análise de indicadores sociais relacionados às pessoas classificadas na categoria DI.

A partir de Crenshaw (2002, p. 177), compreendemos que a abordagem interseccional é aquela "[...] que busca capturar as consequências estruturais e dinâmicas da interação entre dois ou mais eixos da subordinação”, como sexo e raça, que são comumente vetores de desigualdades para o acesso aos direitos sociais, inscritos em nossa Constituição Federal, quais sejam: “[...] a educação, a saúde, a alimentação, o trabalho, a moradia, o transporte, o lazer, a segurança, a previdência social, a proteção à maternidade e à infância, a assistência aos desamparados" (BRASIL, 1988, art. 6º). 
Análises de dados censitários indicam que as pessoas com deficiência no Brasil, em comparação à população geral, têm menores índices de acesso a esses direitos fundamentais, sobretudo a população com DI (OLIVEIRA, 2012). Isso posto, justifica-se a escolha da categoria DI como objeto de análise neste artigo, pois se trata do público mais vulnerável à influência de fatores subjetivos na sua categorização, o que tem se manifestado, por exemplo, em sua maior representatividade no cômputo das matrículas da educação especial nas classes comuns, representando mais de 50 por cento do total dessas matrículas nos últimos anos (MELETTI; BUENO, 2011; GOES, 2014; LOPES, 2018).

Para assinalarmos o conceito de deficiência, é importante lembrar que o Estado brasileiro é signatário da Convenção dos Direitos das Pessoas com Deficiência (ONU, 2006; BRASIL, 2009) e, portanto, compreende que a deficiência se constitui na relação da pessoa com barreiras impostas socialmente, não sendo circunscrita à esfera individual.

Angelucci (2009) nos ajuda nessa leitura ao discutir a ideia de normalidade e anormalidade, pontuando que são padrões cuja constituição está vinculada ao contexto histórico, social e cultural, utilizados para classificar pessoas. Na mesma perspectiva, Cotrin (2010, p. 178) reflete que o “[...] próprio conceito de deficiência deve ser questionado, a partir da perspectiva de que a normalidade não é algo naturalmente estabelecido, mas corresponde às expectativas de determinado grupo e momento social".

A partir da definição de DI estabelecida pela American Association on Intellectual and Developmental Disabilities ${ }^{4}$ (AAIDD), o Estado brasileiro adota a nomenclatura e o conceito desse órgão definido do mesmo modo desde 2002 (VELTRONE; MENDES, 2011), segundo o qual:

A deficiência intelectual é uma deficiência caracterizada por limitações significativas tanto no funcionamento intelectual quanto no comportamento adaptativo, que abrange muitas habilidades sociais e práticas cotidianas. Esta deficiência se origina antes dos 18 anos de idade. (AAIDD, 2018, on-line, tradução nossa).

Articulando essa definição de DI ao conceito de deficiência como uma condição relacional entre sujeito e ambiente (BRASIL, 2009), a ideia de inteligência "normal" também precisa ser vista pelo prisma da construção social ou, em outras palavras, pelo padrão socialmente estabelecido para uma pessoa ser considerada “inteligente". Ademais,

[...] a maneira como historicamente temos construído a pergunta a respeito da diversidade humana persevera, posto que seu efeito, obedecendo sempre à mesma função social, é a criação de dois agrupamentos, polarizados, em que se distingue quem tem legitimidade para ser visto como sujeito dos direitos - o normal - e quem ocupa o lugar de, no máximo, alvo da concessão de favores - o anormal. (ANGELUCCI, 2009, p. 25).

As reflexões da autora são reafirmadas, sobretudo, ao adotarmos a premissa de que o acesso a direitos sociais por uma pessoa com deficiência está diretamente relacionado às suas condições concretas de vida para além do tipo de deficiência, sendo, portanto,

4- Associação Americana de Deficiência Intelectual e de Desenvolvimento. 
determinado também por sexo e raça, os quais, como iremos explorar, constituem-se em eixos que os subordinam a distintas condições de vida.

A partir da teoria do feminismo negro, Crenshaw (2002, p. 172) apresenta uma discussão sobre a "[...] identificação de situações em que a discriminação de gênero é ampliada pela ou combinada com a discriminação racial, ou vice-versa”, tendo como propósito chamar atenção sobre o "[...] fato de que uma gama de violações de direitos humanos fica obscurecida quando não se consideram as vulnerabilidades interseccionais de mulheres marginalizadas e, ocasionalmente, também de homens marginalizados" (CRENSHAW, 2002, p. 178).

Conforme análises de Davis (2016), a priori nenhum desses eixos é mais dominante que outro. Assim, abordaremos brevemente a definição de cada um deles seguindo uma sequência para fins de organização das ideias sem a intenção de classificá-los como mais ou menos preponderantes, trazendo para o bojo de nossas discussões a definição de gênero e raça.

Neste artigo, gênero e raça são concebidos como eixos de subordinação compreendidos por sua dimensão política e em seus princípios históricos, sociais e culturais.

Gênero é um conceito social e historicamente construído que nos auxilia a compreender as diferenças construídas entre homens e mulheres, refutando, assim, sua naturalização (SCOTT, 1995; NICHOLSON, 2000). Este termo começa a ser utilizado por acadêmicas feministas a partir da década de 1970 para afırmar que a desigualdade e a opressão às quais as mulheres eram submetidas não estavam relacionadas tão somente às diferenças de sexo, portanto não eram meramente biológicas, mas, sim, decorrentes de questões socioculturais.

Nessa direção, para Scott (1995, p. 13):

Gênero é a organização social da diferença sexual percebida. 0 que não significa que gênero reflita ou implemente diferenças físicas fixas e naturais entre homens e mulheres, mas sim que gênero é o saber que estabelece significados para as diferenças corporais. Esses significados variam de acordo com as culturas, os grupos sociais e no tempo, já que nada no corpo [...] determina univocamente como a divisão social será estabelecida.

Desse modo, a forma como os corpos expressarão o feminino e o masculino é construída pela sociedade. Isso nos leva à compreensão de que gênero é um elemento de organização de relações de poder em várias instâncias, como família, escola e trabalho, o que pode ser compreendido como viés de gênero na interpretação do papel social do sexo masculino e do feminino.

Também para compreensão do eixo raça, adotamos neste texto a perspectiva social, histórica e cultural. Em Guimarães (1999, p. 153), compreendemos que raça não se refere a atributos dados pelo aparato biológico, mas sim de "[...] construtos sociais, formas de identidade baseadas numa ideia biológica errônea, mas eficaz socialmente, para construir, manter e reproduzir diferenças e privilégios plenamente existentes no mundo social".

Nesse sentido, Schwarcz (2012, p. 34) define que:

Raça é, pois, uma categoria classificatória que deve ser compreendida como uma construção local, histórica e cultural, que tanto pertence à ordem das representações sociais - assim como o 
são fantasias, mitos e ideologias - como exerce influência real no mundo, por meio da produção e reprodução de identidades coletivas e de hierarquias sociais politicamente poderosas.

Compartilhamos com Munanga (2003) o entendimento de que o conceito raça é carregado de ideologia e, por isso, esconde a relação de poder e de dominação que o estrutura e que historicamente tem levado a população negra à privação de direitos sociais (CARNEIRO, 2011), como a educação, efeito esse que se multiplica na articulação com o atributo sexo, e tem reflexos singulares sobre os processos de escolarização dessa população.

Trazemos a ideia de escolarização para o conjunto de nossas discussões por compreender que o direito à educação escolar - que abrange ingresso, permanência e conclusão da educação básica com aprendizagem - é fundamental para a garantia de todos os demais direitos sociais (MONTEIRO, 2003). Considerando a ausência e a precariedade de dados oficiais relativos à aprendizagem na educação escolar da população com DI no Brasil, utilizamos informações do Censo 2010, especificamente sobre a taxa de alfabetização - que expressa o percentual de pessoas de 5 ou mais anos de idade que sabe ler e escrever pelo menos um bilhete simples em seu idioma (IBGE, 2010).

Com esses dados, buscamos apreender o perfil da população com DI por meio da perspectiva interseccional.

Adotar uma abordagem interseccional para apreender aspectos da condição de vida das pessoas com DI como um importante fator para subsidiar análises, planejamento e avaliação de políticas públicas é fundamental, porque a justaposição de diferentes eixos de subordinação pode ser razão do aprofundamento da situação de exclusão desses sujeitos. Como ilustração disso, ao analisar dados do Banco Mundial e da Organização das Nações Unidas (ONU) referentes ao ano 2000, Goes (2014, p. 33) mostra a estreita ligação entre pobreza e deficiência apontando que "[...] um em cada vinte habitantes do planeta apresenta alguma deficiência, e, nos países mais pobres, essa proporção cai para um em cada cinco habitantes".

Isso evidencia que não é unívoca a forma como as desigualdades afetam a vida de uma população e dos diferentes grupos sociais. Portanto é preciso compreender a DI na relação com diferentes eixos de subordinação e problematizar como eles se imbricam para que possamos debater possíveis enfrentamentos a partir de políticas públicas de corte social.

Uma das formas de apreender a condição de vida da população é analisar os indicadores sociais, importante fonte de informação à formulação, implementação, acompanhamento e avaliação de políticas públicas (JANNUZZI, 2005). A partir de Miles (1985) e produções da ONU, o autor explicita que

[...] os indicadores apontam, indicam, aproximam, traduzem em termos operacionais as dimensões sociais de interesse definidas a partir de escolhas teóricas ou políticas realizadas anteriormente. Prestam-se a subsidiar as atividades de planejamento público e a formulação de políticas sociais nas diferentes esferas de governo, possibilitam o monitoramento das condições de vida e bemestar da população por parte do poder público e da sociedade civil e permitem o aprofundamento da investigação acadêmica sobre a mudança social e sobre os determinantes dos diferentes fenômenos sociais. (JANNUZZI, 2005, p. 138). 
Ainda, de acordo com o autor, para o acompanhamento de uma política pública podemos contar com dados administrativos e "[...] estatísticas públicas (produzidas pelo IBGE e outras instituições), que, reorganizados na forma de taxas, proporções, índices ou mesmo em valores absolutos, transformam-se em indicadores sociais" (JANNUZZI, 2005, p. 139).

Nesse sentido, tais indicadores são traduzidos em cifras tangíveis e operacionais, dimensões relevantes da realidade social (JANNUZZI, 2005). Para tanto, sempre que possível,

[...] deve-se procurar empregar indicadores de boa cobertura territorial ou populacional, que sejam representativos da realidade empírica em análise. Essa é uma das características interessantes dos indicadores sociais produzidos a partir dos censos demográficos, o que os tornam tão importantes para o planejamento público no país. (JANNUZZI, 2005, p. 140).

Considerado o escopo dessa pesquisa, buscamos apreender quem são as pessoas classificadas com DI no Brasil, considerando os seguintes indicadores sociais: ocupação, rendimento nominal mensal e alfabetização.

A preocupação central é analisar como esses dados em intersecção com raça e sexo podem contribuir para o planejamento de políticas educacionais, haja vista que submetem sujeitos a distintas condições de vida e imprimem marcas que mantêm e/ou aprofundam desigualdades. Assim, a pesquisa norteia-se pela seguinte questão: quais as possíveis implicações dos indicadores sociais referentes à população com DI para a atual política nacional de educação especial?

Esse questionamento é explorado a partir das informações produzidas pelo IBGE no âmbito do Censo Demográfico ${ }^{5}$ e publicadas em seu portal, o que tomamos como fonte de dados. Contudo, antes de apresentarmos o percurso metodológico deste estudo, é importante considerar alguns aspectos da formulação de indicadores sociais pelo IBGE sobre as pessoas com deficiência no Brasil.

\section{Indicadores sociais do IBGE sobre a população com deficiência no Brasil}

Dados sobre as pessoas com deficiência foram produzidos pelo IBGE já no primeiro recenseamento brasileiro, em 1872 (IBGE, 2018a). Mas foi em 1989 que se determinou a “[...] inclusão de questões concernentes às pessoas com deficiência no Censo Demográfico de 1991 e nos anos subsequentes" (IBGE, 2018a, p. 1). Assim, tais questões estiveram presentes nos Censos de 1991, 2000 e 2010. No último recenseamento nacional, o IBGE buscou

[...] captar a percepção da população sobre sua dificuldade em ouvir, enxergar e caminhar ou subir escadas, mesmo contando com facilitadores como aparelhos auditivos, lentes de contato e bengalas. 0 questionário buscava também identificar deficiência intelectual e mental através da compreensão do informante sobre a dificuldade em realizar suas atividades habituais. (IBGE, 2018a, p. 2).

\footnotetext{
5- "Os censos demográficos são pesquisas estatísticas cujo levantamento consiste na visita a todos os domicílios de um país e constituem a única fonte de referência para o conhecimento das condições de vida da população em todos os municípios e em seus recortes territoriais internos - distritos, bairros e localidades, rurais ou urbanos". Disponível em: https://bit.ly/2g0e6G4. Acesso em: 13 out. 2019.
} 
Desse modo, o Censo Demográfico identifica quatro categorias de deficiência: auditiva (DA), física (DF) ${ }^{6}$, visual (DV) e mental ou intelectual (DI) ${ }^{7}$. Devido à metodologia empregada pelo IBGE para identificar as pessoas com deficiência no país, estudos do campo da educação especial (SASSAKI, 2003; MELETTI; BUENO, 2011, 2013) têm questionado a validade dessas informações, considerando que os resultados podem não retratar efetivamente a realidade em função da possibilidade dos respondentes do questionário interpretarem as questões de forma equivocada. Na leitura desses autores, expressão disso é o alto índice de pessoas classificadas na categoria DV que, em 2000 e 2010, tiveram maior percentual em relação às demais categorias de deficiência investigadas pelo Censo Demográfico no país. Para os autores, esses resultados exprimem limitações metodológicas do Censo, de modo que pessoas que não se enquadram na condição de DV podem ter se declarado ou sido declaradas como tal (SASSAKI, 2003; MELETTI; BUENO, 2011, 2013).

Com o intuito de aprimorar a discussão sobre o monitoramento de indicadores relativamente à população brasileira e contribuir para a identificação de eventuais lacunas nas suas pesquisas, em 2018, o IBGE publicou o documento Panorama nacional e internacional da produção de indicadores sociais (IBGE, 2018b). No que tange às informações sobre pessoas com deficiência no Censo 2010, essa publicação se vale das recomendações do Grupo de Washington $(\mathrm{GW})^{8}$ para estatísticas sobre pessoas com deficiência para realizar uma releitura daqueles dados, classificando como pessoa com deficiência apenas aquelas que responderam, em uma ou mais questões do Censo 2010, muita dificuldade ou não consegue de modo algum. Assim, foram excluídas as pessoas, até então computadas, que deram como resposta ter alguma dificuldade. Vale dizer que este parâmetro não se aplica à DI, visto que a pergunta sobre essa condição permite apenas sim ou não como categorias de respostas.

A principal implicação dessa mudança reside no seguinte fato:

[...] a população total de pessoas com deficiência residentes no Brasil captada pela amostra do Censo Demográfico 2010 não se faz representada pelas 45.606 .048 pessoas, ou 23,9\% das 190.755.048 pessoas recenseadas nessa última operação censitária, mas sim por um quantitativo de 12.748.663 pessoas, ou 6,7\% do total da população registrado pelo Censo Demográfico 2010. (IBGE, 2018b, p. 5).

A adoção da linha de corte do GW teve significativo impacto, como se observa pelo decréscimo do percentual de pessoas por tipo de deficiência em relação à população sem deficiência no país. A saber, respectivamente sem e com a aplicação da linha de corte do GW: DV, de 18,8 para 3,4 por cento; DA, de 5,1 para 1,1 por cento; $\mathrm{DF}$, de 7,0 para 2,3 por

6- Utilizamos o termo deficiência física como sinônimo do termo deficiência motora utilizado pelo IBGE.

7- No Censo 2010, deficiência mental e intelectual são termos sinônimos. Portanto referem-se ao mesmo grupo de pessoas.

$\mathbf{8}$ - "Tendo-se como horizonte a comparabilidade internacional das estatísticas sobre pessoas com deficiência, foi fundado, no âmbito da Comissão de Estatística da ONU, o Grupo de Washington sobre Estatísticas das Pessoas com Deficiência (Washington Group on Disability Statistics)" (IBGE, 2018a, on-line). 0 grupo é "[... . composto por representantes de Institutos Oficiais de Estatística e organizações representantes da sociedade civil. Como representante oficial do Brasil, o IBGE participa desde o início da formação do grupo, em 2001, acompanhando as discussões e estudos propostos" (IBGE, 2018a, on-line). 
cento (IBGE, 2018a). Como já anunciado, os critérios do GW não afetaram o percentual de pessoas com DI, que permaneceu em 1,4 por cento.

Considerando o cômputo total de cada tipo de deficiência, registra-se que todas diminuíram, exceto DI. Contudo uma diferença importante se observa no percentual de cada categoria quando tomamos como referência apenas o grupo de pessoas com deficiência, conforme ilustrado no Gráfico 1.

Gráfico 1 - Percentual de cada tipo de deficiência entre as pessoas categorizadas em uma dessas condições - Brasil - 2010

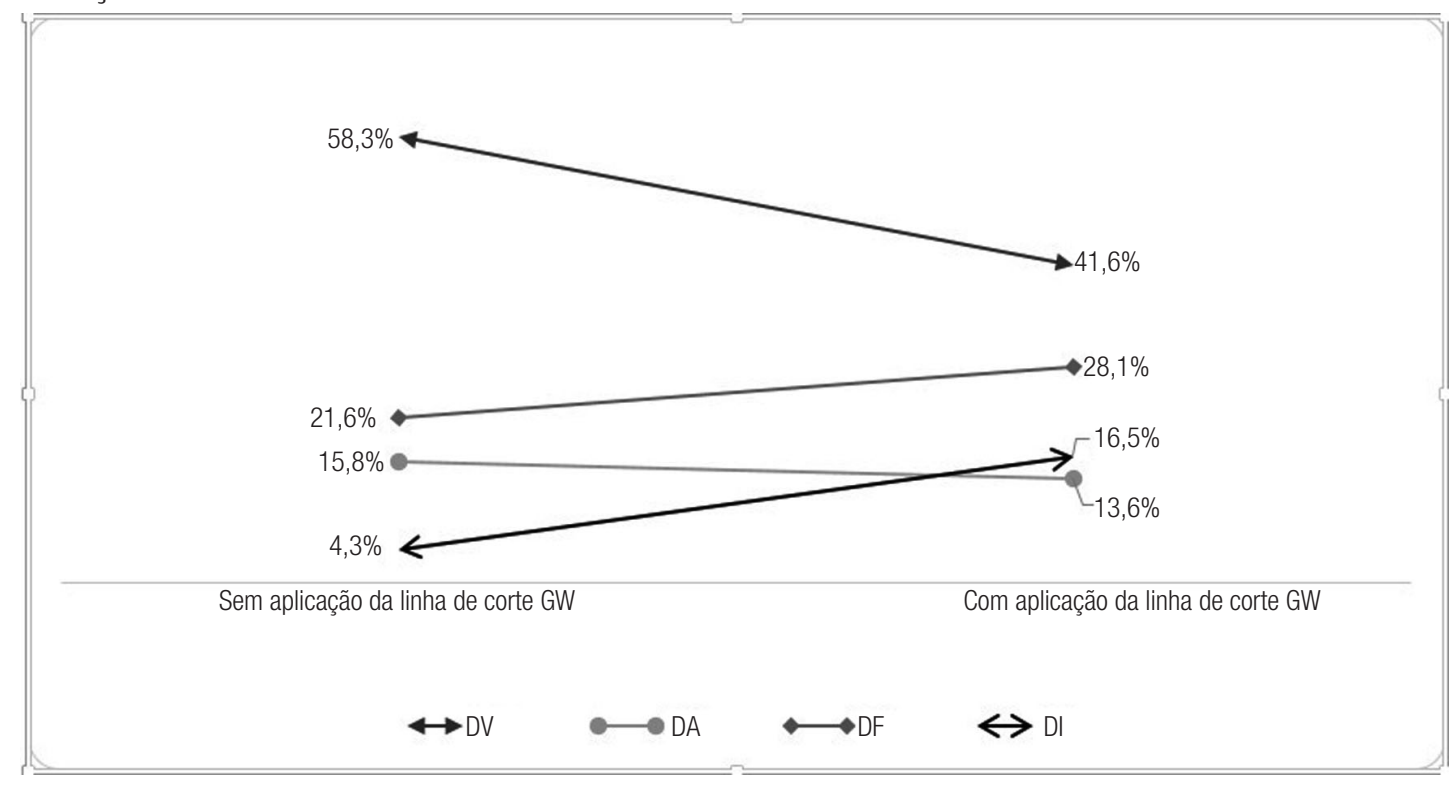

Fonte: Dados extraídos do Censo 2010 (IBGE, 2010) e organizados pelas autoras.

Legenda: GW - Grupo de Washington.

Os dados do gráfico acima revelam que, em termos percentuais, somente as categorias DV e DA diminuíram. DV permaneceu na primeira posição no ranking, destacando-se sua acentuada diferença ( $-16,7$ por cento), o que sugere a comprovação dos questionamentos de Sassaki (2003) e Meletti e Bueno (2011, 2013) sobre a metodologia até então utilizada pelo IBGE. Já DA, embora tenha apresentado diminuição do cômputo total e percentual, passou da terceira para quarta posição em função da significativa diferença percentual da categoria DI, que passou a representar 16,5 por cento da população com deficiência, ocupando a terceira posição. Embora tenha permanecido na segunda posição, DF também apresentou aumento de 7,5 por cento.

Apesar dessas discrepâncias, como destaca o próprio instituto (IBGE, 2018b, p. 7), “[...] não se trata de uma correção dos números que foram divulgados”. A releitura incide sobre a análise dos resultados. 
Postas essas questões, neste artigo trabalhamos com os dados censitários considerando a linha de corte do GW, que, embora não tenha incidido sobre a população com DI em relação ao total da população, alterou significativamente seu percentual dentro do grupo de pessoas com deficiência, como foi demonstrado anteriormente. Vale dizer, essas considerações não refutam em absoluto os questionamentos de Sassaki (2003) e Meletti e Bueno (2011, 2013), já que, mesmo com a aplicação da linha de corte do GW, pode haver imprecisões nas informações produzidas pelo IBGE, o que demanda estudos mais específicos. Mas vale lembrar que os questionamentos dos autores antecedem à releitura do IBGE sobre os dados relativos às pessoas com deficiência e, portanto, referemse a um universo distinto daquele que tratamos neste texto.

Ademais, atualmente, os dados do Censo 2010 são os únicos dados produzidos em escala nacional sobre a caracterização das pessoas com deficiência no Brasil. Assim, ainda que sejam limitados, tais dados podem revelar e colaborar para a compreensão de fatores interseccionais que marcam a condição de vida dessas pessoas, nos permitindo a identificação de diferentes eixos de subordinação, o que é fundamental para a discussão de políticas públicas, entre elas, a de educação, considerando que as informações sobre a escolarização da população do país são indicações de possíveis enfrentamentos de desigualdades econômicas, sociais e culturais. Nesse sentido, concordamos que, apesar de "[...] limitados, os dados disponíveis [do IBGE] podem revelar como o atendimento educacional para esta população está evoluindo" (MELETTI; BUENO, 2011, p. 375), para mencionar um dos aspectos da política nacional de educação especial.

No Censo Demográfico, são localizados indicadores que permitem apreender quem são as pessoas com DI no Brasil em termos de ocupação, renda, sexo, raça ou cor e taxa de alfabetização, conforme explicitamos a seguir na apresentação do percurso metodológico do estudo.

\section{Metodologia}

Estudos da área de educação especial (BUENO; MELLETI, 2011; LOPES, 2018; PRIETO et al., 2018) têm se reportado ao Censo Demográfico para contextualizar quem são as pessoas com deficiência no Brasil - o que reforça a ideia de que os dados do IBGE são uma referência, demonstrando sua legitimidade institucional e política -, apesar das dúvidas que imprimem quanto à sua legitimidade técnica e científica (SASSAKI, 2003; MELETTI; BUENO, 2011, 2013). Valemo-nos, assim, dos dados do Censo 2010 por serem os mais recentes até o momento, visto que no Brasil esse recenseamento é realizado a cada dez anos e, sobretudo, pela falta de estudos sobre a população com deficiência considerando a atual releitura do IBGE a partir das recomendações do GW.

Todos os dados produzidos pelo IBGE são organizados em tabelas e podem ser extraídos do Sistema IBGE de Recuperação Automática (Sidra), disponível no portal eletrônico do instituto, onde consta seu Banco de tabelas estatísticas, que permite acesso por filtros (indicadores, população, economia e geociências) correspondentes a resultados de diferentes tipos de pesquisa, a exemplo do Censo Demográfico, presente no filtro 
População. As informações desse filtro estão classificadas nos tópicos Geral, Universo e Amostra, organizadas em sinopses e disponiveis em tabelas que tratam dos temas população, domicílios e/ou território. Além disso, os dados podem ser desagregados para os níveis Brasil, região geográfica e unidade da federação.

0 único que contém informações sobre a população com deficiência é o tópico Amostra, que corresponde a dados de 6.192.332 domicílios brasileiros, o que significa "[...] uma fração amostral efetiva da ordem de 10,7\% para o país como um todo” (BRASIL, 2010, on-line). Para fins dessa pesquisa, trabalhamos apenas com dados do subtema População com deficiência do qual, em um conjunto de dez tabelas, somente em seis é possível extrair informações desagregadas por tipo de deficiência e, por isso, específicas sobre a população com DI. Dessas, elegemos as que contêm informações relacionadas à ocupação, rendimento nominal mensal, sexo, raça ou $\operatorname{cor}^{9}$ e alfabetização.

É importante explicitar também que, ao desagregar os dados por categoria de deficiência cruzando com outros indicadores do Censo 2010, é possível apenas identificar o número de ocorrência de cada tipo de deficiência, e não o número total de pessoas. Isso porque uma pessoa classificada em mais de uma categoria de deficiência é contabilizada mais de uma vez nos dados desagregados ${ }^{10}$.

Os dados foram reorganizados em tabelas e gráficos e discutidos a partir do referencial teórico que considera a intersecção entre dois ou mais eixos de subordinação, o que é possível localizar nos estudos de Crenshaw (2002), Mendes e Lourenço (2009), Carneiro (2011), Davis (2016) e Pereira (2016).

\section{Resultados e discussões: leitura interseccional dos indicadores sociais e suas implicações para a política de educação especial}

Buscamos apreender o perfil da população com DI considerando alguns aspectos que estruturalmente são eixos de subordinação por conferir às pessoas condições desiguais no acesso aos direitos sociais.

Iniciando pelo eixo sexo, no Gráfico 2 podemos observar que a maioria da população com DI é do sexo masculino (54 por cento). Embora sem uma diferença significativa, não segue a tendência do total da população brasileira (exceto pessoas com uma das deficiências investigadas pelo IBGE) que está distribuída entre 49,4 por cento do sexo masculino e 50,6 por cento do sexo feminino. 0 agrupamento de pessoas com DI por sexo não segue também o grupo de pessoas com pelo menos uma das deficiências investigadas, que estão distribuídas entre 43,9 por cento do sexo masculino e 56,1 por cento do feminino.

Embora com menor diferença percentual entre masculino e feminino, a caracterização da população com DI por sexo no país se assemelha mais ao que ocorre no contexto escolar, que tem sido composto por 66 por cento de estudantes com DI

\footnotetext{
9- 0 IBGE (2010, on-line) investigou a cor ou raça declarada pela pessoa, com as seguintes opções de resposta: branca; preta; amarela (de origem oriental: japonesa, chinesa, coreana etc.); parda; e indígena.

10- Por exemplo: em um grupo de 30 pessoas com deficiência, sendo 25 com DV e 5 com DI associada à DA, nos dados desagregados por categoria de deficiência contabiliza-se: 25 com DV, 5 com DI e 5 com DA, portanto, totalizando 35.
} 
do sexo masculino e 33 por cento do feminino (PRIETO; SOUSA, 2006; PEREIRA, 2016; LOPES, 2018), indicando possíveis relações entre a classificação de alunos na categoria DI influenciadas pelo viés de gênero, ou seja, as distintas “[...] expectativas e estereótipos dos papéis sexuais que a sociedade atribui aos indivíduos em função do gênero, e que resultam num aumento da expectativa e da cobrança sobre meninos, e ao mesmo tempo de uma tolerância maior em relação ao baixo desempenho de meninas" (MENDES; LOURENÇ0, 2009, p. 418).

Ao considerarmos a caracterização por cor ou raça (Gráfico 2), os dados do IBGE (2010) informam que a população com DI é composta por 45,9 por cento de pessoas declaradas brancas, 52,6 por cento declaradas negras ${ }^{11}$ - sendo 8,5 por cento pretas e 44,2 por cento pardas -, 1,1 por cento amarelas, 0,4 por cento indígenas e nenhuma sem declaração de cor ou raça. Esses dados seguem a distribuição da população geral no qual pessoas declaradas negras representam cerca de 50 por cento de toda a população do país (IBGE, 2010).

Gráfico 2 - Percentual da população com DI, segundo o sexo e a cor ou raça

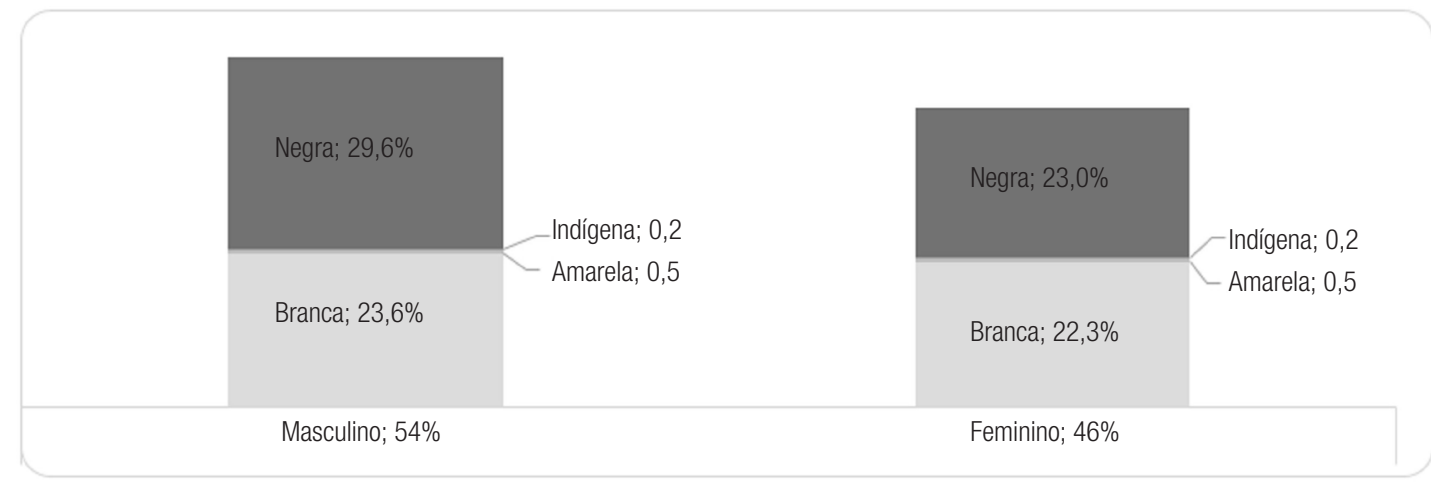

Fonte: Dados extraídos do Censo 2010 (IBGE, 2010) e organizados pelas autoras.

Essa distribuição ocorre também entre as demais categorias de deficiência, em que as pessoas declaradas negras representam 53,5 por cento do grupo de pessoas com DV, 50,1 por cento com DF e 47,8 por cento com DA. Quando observamos o percentual de pessoas com DI pelo cruzamento entre sexo e cor ou raça (Gráfico 2), identificamos que a maioria é composta por homens declarados negros (29,6 por cento), seguido por homens brancos (23,6 por cento), mulheres negras (23 por cento) e mulheres brancas (22,3 por cento). Esses dados se distinguem da população geral, que é composta majoritariamente por mulheres negras (IBGE, 2010). Assim, junto com o viés de gênero, a questão racial marca a classificação de pessoas na categoria DI.

É sabido que a população negra, por questões estruturais, sofre desvantagens e desigualdades no acesso a direitos sociais (CARNEIRO, 2011), o que por si só exige a

11- A partir de Osório (2003), compreendemos que a soma do número de pessoas declaradas pretas e pardas constitui o total da população negra no Brasil. 
busca por compreender como essas questões se imbricam bem como as possíveis ações de enfrentamento por via de políticas públicas.

É importante destacar, contudo, que os dados utilizados neste estudo permitiram a articulação do eixo raça apenas com o eixo sexo, de modo que os dados do IBGE (2010) sobre a população com deficiência no país não permitem uma análise interseccional que articule deficiência e raça com outros aspectos.

$\mathrm{Na}$ busca por apreender informações sobre possibilidades socioeconômicas, trabalhamos com dados sobre população ocupada e classes de rendimento nominal mensal (IBGE, 2010b). Vale esclarecer que o IBGE (2010, on-line) define população ocupada como “[...] pessoas que, num determinado período de referência, trabalharam ou tinham trabalho, mas não trabalharam (por exemplo, pessoas em férias)". 0 rendimento nominal mensal refere-se à quantidade de salários-mínimos recebidos pela pessoa ocupada em cada mês trabalhado (IBGE, 2010).

Em relação a "classes de rendimento nominal mensal" no grupo da população ocupada, com algum tipo de deficiência e com 10 anos ou mais de idade (24.923.902 pessoas), os dados evidenciam que apenas 1,7 por cento (ou seja, 419.769) desse total correspondia à categoria DI, sendo, assim, a menos contemplada pela ocupação, seguida pelas categorias DA, com 14,8 por cento, DF, com 15,9 por cento, e DV, com 67,7 por cento (IBGE, 2010). Portanto a população com DI parece carecer de um olhar específico no âmbito das políticas de inserção no mercado de trabalho, questão que certamente se articula com o cenário da escolarização dessas pessoas e, por isso, indica a necessidade da abordagem interseccional para as políticas de educação no país.

Ao considerarmos as pessoas com DI ocupadas e, consequentemente, contempladas por rendimento nominal mensal, a partir do Gráfico 3, é possível observar que - no cômputo do percentual dos quatro tipos de deficiência aqui considerados e em todas as classes de rendimento nominal mensal - as pessoas com DI estão no nível mais baixo da escala em todas as faixas de renda, exceto o índice "sem rendimento", que corresponde às pessoas que contavam apenas com benefícios, a exemplo do Benefício de Prestação Continuada - BPC ${ }^{12}$ (IBGE, 2010), sendo o maior grupo nessa classe.

Esse dado sugere, mais uma vez, a necessidade de considerações específicas a esse público que, dentro do grupo de pessoas com deficiência, sofre maior desvantagem em relação aos demais, o que pode ser consequência também do valor social conferido ao atributo intelectual na atividade laboral. Como apontado por Goes (2014), é notória a maior vulnerabilidade das pessoas com DI, tanto em relação às sem deficiência como entre sujeitos classificados nas outras categorias, haja vista que, em nossa sociedade, a condição intelectual é um atributo altamente valorizado, persistindo a ideia de que este, supostamente, "[...] habilita as pessoas a enfrentarem os mais variados desafios impostos por uma sociedade competitiva e com avanços tecnológicos a passos largos” (GOES, 2014, p. 21).

12- 0 benefício de prestação continuada é a garantia de um salário-mínimo mensal à pessoa com deficiência e ao idoso com 65 (sessenta e cinco) anos ou mais que comprovem não possuir meios de prover a própria manutenção nem de tê-la provida por sua família. (BRASIL, 1993, art. 20). 
Gráfico 3 - Percentual de pessoas de 10 anos ou mais de idade, ocupadas, por tipo de deficiência e classes de rendimento nominal mensal

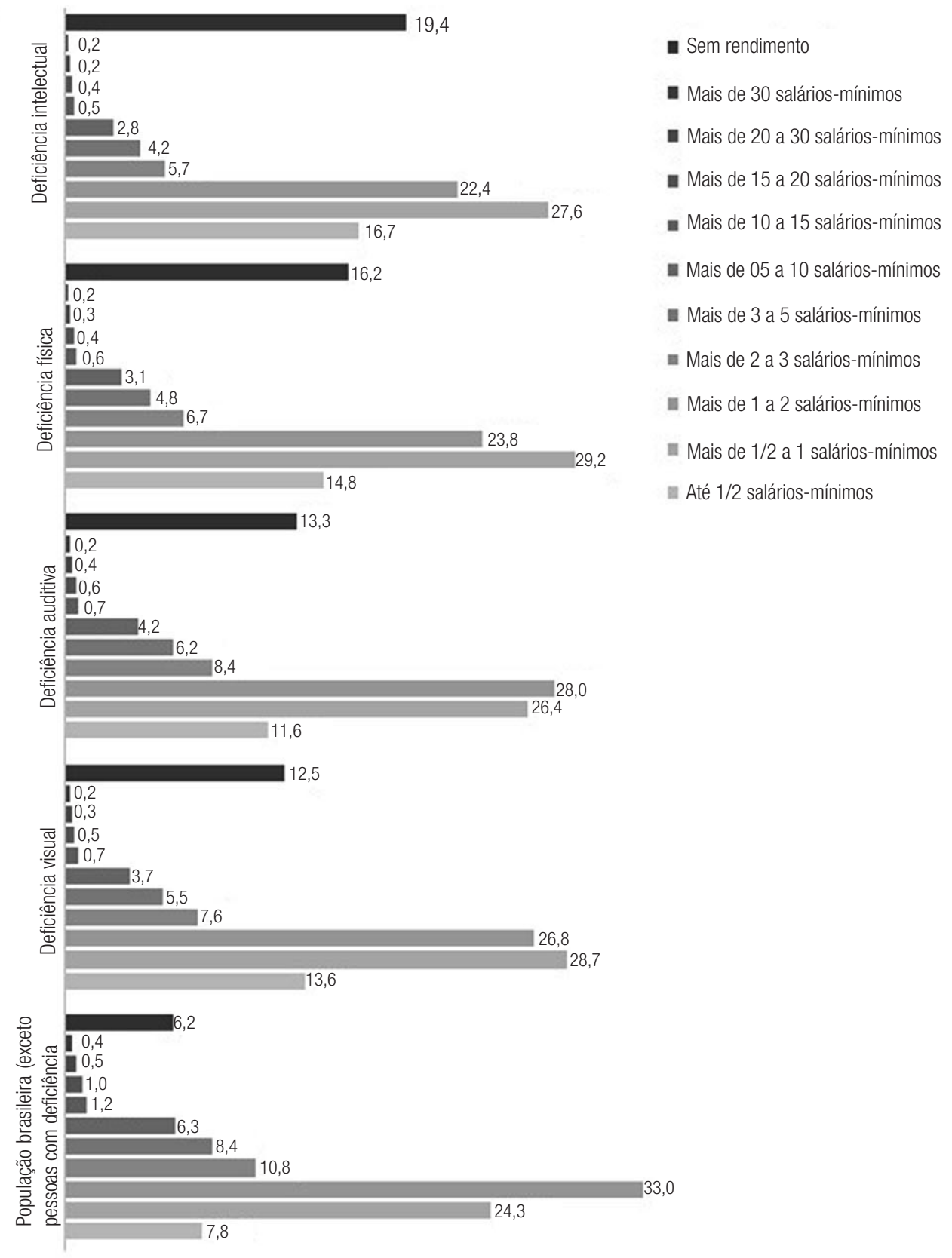

Fonte: Censo 2010 (IBGE, 2010) e editado pelas pesquisadoras.

Nota: Salário-mínimo $=510$ reais no ano de 2010. 
Na tentativa de apreender demais especificidades da possibilidade socioeconômica das pessoas com DI, organizamos os dados das classes de rendimento nominal mensal desagregando-os por sexo (Gráfico 4).

Gráfico 4 - Percentual de pessoas com DI de 10 anos ou mais de idade, ocupadas na semana de referência, por sexo e classes de rendimento nominal

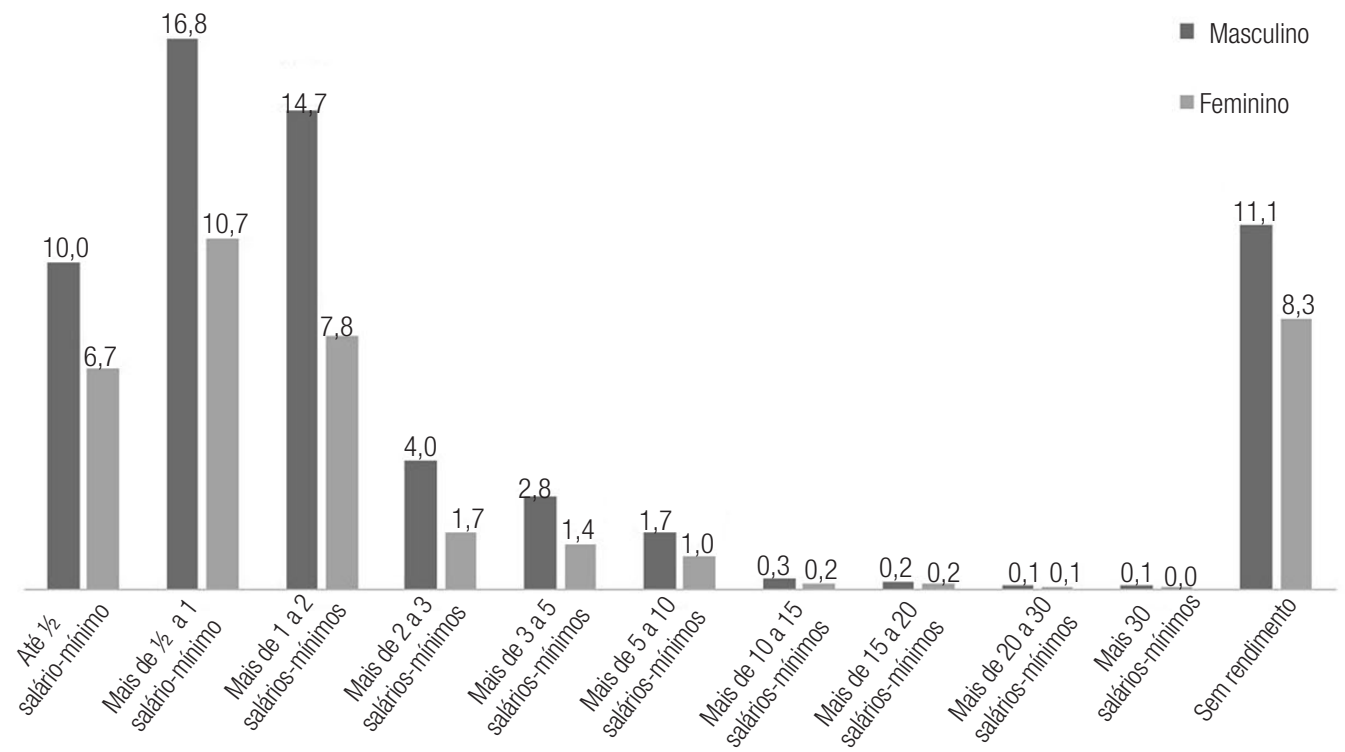

Fonte: Censo 2010 (IBGE, 2010) e editado pelas pesquisadoras.

Os dados do Gráfico 4 indicam que quanto mais alta a classe de rendimento, menos pessoas com DI as ocupam, o que se destaca entre as faixas "mais de 10" e "mais de 30 salários-mínimos”. A classe com maior percentual de pessoas com DI é a de mais de $1 / 2$ a um salário-mínimo que, ao compararmos com dados do Gráfico 3, podemos identificar que esse aspecto não se repete para toda a população brasileira nem mesmo para algumas das demais categorias de deficiência, mostrando que as pessoas com DI ocupam a escala mais desfavorecida no quesito rendimento nominal mensal.

Além dessa desvantagem, outra se mostra evidente quando comparamos o grupo do sexo masculino e do feminino, sendo que o primeiro se fez presente em maior percentual em todas as classes, inclusive em "sem rendimentos".

Considerando que na classe "sem rendimentos" encontram-se os beneficiários do BPC, podemos questionar: o sexo feminino sofreu desigualdades no acesso a esse benefício motivadas por questões de gênero, reproduzindo o que ocorre em toda a população brasileira?

Observa-se ainda que quanto maior a classe de rendimento, menor é a distância entre os sexos, sendo que, a partir de dez salários-mínimos, ambos caem para menos de 1 por cento e, na categoria mais de trinta salários, o percentual do sexo feminino é nulo, indicando mais uma vez o gênero como possível vetor de desigualdades entre o grupo de pessoas com DI, de modo que esses dados sugerem desvantagem do sexo feminino em relação ao masculino, reproduzindo o que ocorre entre a população sem deficiência e 
também entre os demais tipos de deficiência abordados pelo IBGE (2010). Como veremos na análise sobre alfabetização apresentada a seguir, esses dados não estabelecem vínculos com as informações relacionadas à escolarização das mulheres com DI.

Além das informações sobre renda, buscamos apreender informações sobre a escolarização das pessoas com DI a partir de indicadores de alfabetização (Gráfico 5).

Gráfico 5 - Percentual de pessoas de 5 anos ou mais de idade, por tipo deficiência e alfabetização

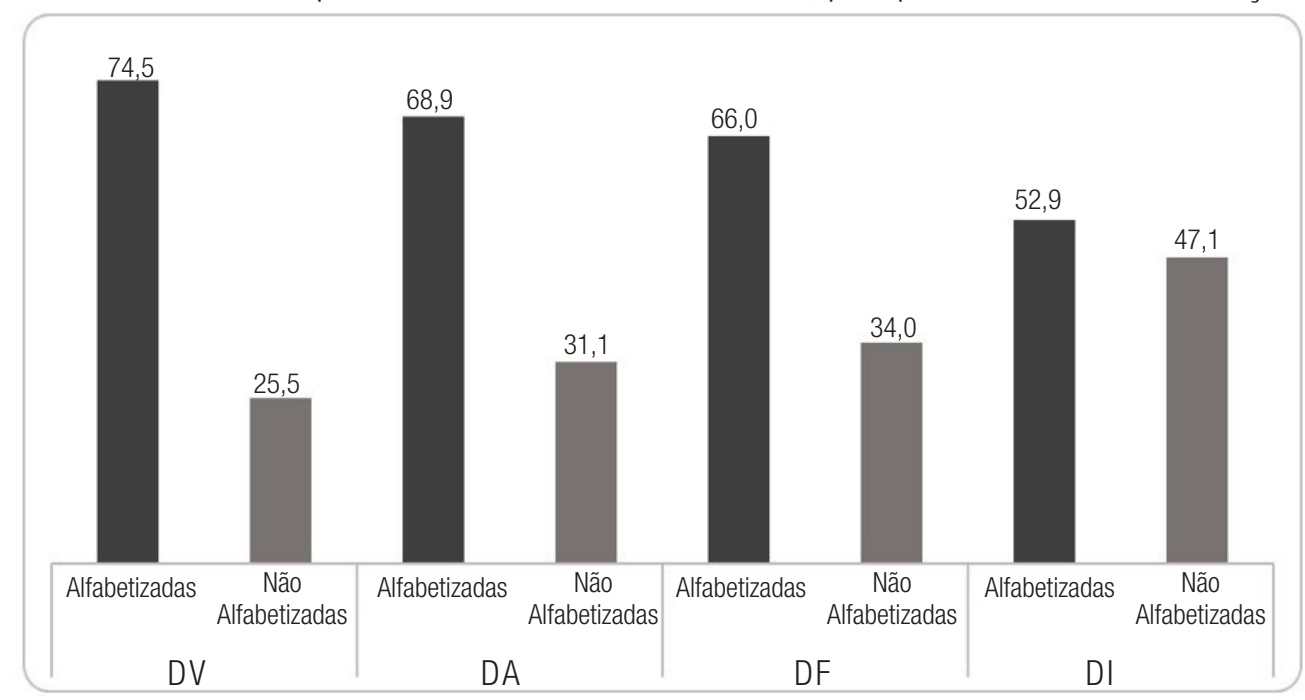

Fonte: Censo 2010 (IBGE, 2010) e editado pelas pesquisadoras.

Observando inicialmente a categoria DI entre os demais tipos de deficiência, o primeiro aspecto relevante a se considerar é que a população com DI tem menor percentual de pessoas consideradas alfabetizadas (52,9 por cento).

Considerando a alfabetização de pessoas com DI em relação ao sexo, observa-se, nos dados do Gráfico 6, que questões de gênero parecem não ter influência nas oportunidades de alfabetização, de modo que em ambos os sexos a maioria (pouco mais da metade de cada grupo) era alfabetizada.

Gráfico 6 - Percentual de pessoas com DI de 5 anos ou mais de idade, por sexo e alfabetização

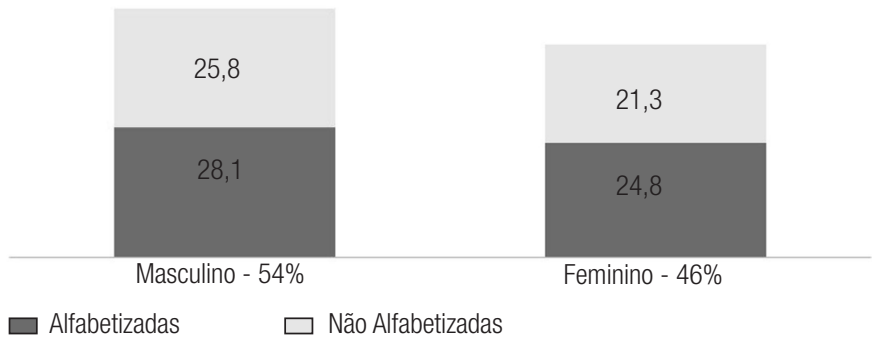

Fonte: Censo 2010 (IBGE, 2010) e editado pelas pesquisadoras. 
Comparando esses dados aos da população geral, evidencia-se grande discrepância, uma vez que, entre esta, o percentual de pessoas não alfabetizadas é de 8,5 por cento, sendo 4,6 por cento do sexo masculino e 3,9 por cento do feminino. Ademais, aqui é possivel observar ligeira diferença de oportunidades entre os sexos, com menor percentual de pessoas não alfabetizadas do sexo feminino.

\section{Considerações finais}

Os dados indicam que, em comparação com as demais categorias de deficiência abordadas pelo Censo 2010, DI é a que mais sofre desvantagens nos indicadores sociais de acesso ao trabalho, à renda e à alfabetização.

Além disso, questões de gênero se mostram influentes como um eixo de subordinação, conferindo ao sexo feminino menos acesso aos direitos sociais abordados neste estudo, ainda que componha o menor percentual de todo o grupo de pessoas com DI no país.

Outra consideração importante refere-se à identificação racial das pessoas com DI no país, que parece influenciar a classificação de sujeitos nessa categoria de deficiência. É importante destacar que os dados utilizados neste estudo nos permitiram articular o eixo raça apenas com o eixo sexo, de modo que os dados analisados não permitem uma leitura interseccional que articule cor ou raça com outros indicadores, como ocupação, renda e alfabetização.

Por fim, os resultados indicam a necessidade de um olhar específico e uma perspectiva interseccional a esse público, que, dentro do grupo de pessoas com deficiência, demonstra sofrer maior desvantagem em relação aos demais no acesso aos direitos sociais previstos na Constituição Federal do país. Conforme os dados apresentados, podemos apreender a emergente necessidade de que sejam produzidos mais dados sobre essas pessoas, assim como que estes possam ser desagregados, permitindo análises interseccionais com vistas à compreensão de como diferentes eixos de subordinação afetam a vida das pessoas com DI no Brasil e indicando ações no âmbito das políticas educacionais especificamente dedicadas ao enfrentamento das desigualdades que marcam singularmente a situação das pessoas com DI quando comparadas à população geral e, também, a outras categorias de deficiência. Ademais, pesquisas que articulem indicadores sociais a representações sociais sobre gênero e raça associados à deficiência são necessárias para o aprofundamento da compreensão sobre a população focalizada pela política de educação especial (BRASIL, 2008), em face da precariedade de estudos que compreendam esses sujeitos para além da deficiência, considerando outros atributos de sua constituição humana e que impactam em suas oportunidades de acesso aos direitos sociais, sobretudo à educação.

\section{Referências}

AAIDD. American Association on Intellectual and Developmental Disabilities. Intellectual Disability: Definition. Silver Spring: AAIDD, [2018]. Disponível em: https://bit.ly/2KJqWUf. Acesso em: 5 jul. 2018.

ANGELUCCI, Carla Biancha. 0 educador e o forasteiro: depoimentos sobre encontros com pessoas significativamente diferentes. 2009. Tese (Doutorado em Psicologia) - Universidade de São Paulo, São Paulo, 2009. 
BRASIL. [Constituição (1988)]. Constituição da República Federativa do Brasil. Diário Oficial da União: seção 1, Brasília, DF, 5 out. 1988.

BRASIL. Decreto $n^{0}$ 6.949, de 25 de agosto de 2009. Promulga a convenção internacional sobre os direitos das pessoas com deficiência e seu protocolo facultativo, assinados em Nova York, em 30 de março de 2007. Diário Oficial da União, Brasília, DF, 25 ago. 2009.

BRASIL. Lei nº 8.742, de 7 de dezembro de 1993. Dispõe sobre a organização da Assistência Social e dá outras providências. Diário Oficial da União, Brasília, DF, 8 dez. 1993.

BRASIL. Secretaria de Educação Especial. Política nacional de educação especial na perspectiva da educação inclusiva. Brasília, DF: MEC, 2008.

CARNEIRO, Sueli. Racismo, sexismo e desigualdade no Brasil: consciência em debate. São Paulo: Selo Negro, 2011.

COTRIN, Jane Teresinha Domingues. Itinerários da psicologia na educação especial: uma leitura crítica em psicologia escolar. 2010. Tese (Doutorado em Psicologia Escolar e do Desenvolvimento Humano) Instituto de Psicologia, Universidade de São Paulo, São Paulo, 2010.

CRENSHAW, Kimberlé. Documento para o encontro de especialistas em aspectos da discriminação racial relativos ao gênero. Estudos Feministas, Florianópolis, v. 10, n. 1, p. 171-188, 2002.

DAVIS, Angela. Mulheres, raça e classe. São Paulo: Boitempo, 2016.

GOES, Ricardo Schers de. Escolarização de alunos com deficiência intelectual: as estatísticas educacionais como expressão das políticas de educação especial no Brasil. 2014. Tese (Doutorado em Educação) - Pontifícia Universidade Católica de São Paulo, São Paulo, 2014.

GUIMARÃES, Antônio Sérgio Alfredo. Raça e os estudos de relações raciais no Brasil. Novos Estudos CEBRAP, São Paulo, n. 54, p. 147-156, 1999.

GONZALEZ, Roseli Kubo. Educação especial e processos de encaminhamento para salas de recursos: relações de gênero e cor/raça. 2013. Tese (Doutorado em Educação) - Faculdade de Educação, Universidade de São Paulo, São Paulo, 2013.

IBGE. Instituto Brasileiro de Geografia e Estatística. Censo Demográfico 2010: características gerais da população, religião e pessoas com deficiência. Rio de Janeiro: IBGE, 2010. Disponível em: https://biblioteca. ibge.gov.br/visualizacao/periodicos/94/cd_2010_religiao_deficiencia.pdf. Acesso em: 20 ago. 2018.

IBGE. Instituto Brasileiro de Geografia e Estatística. Censo Demográfico 2010: nota técnica 01/2018 releitura dos dados de pessoas com deficiência no Censo Demográfico 2010 à luz das recomendações do Grupo de Washington. Rio de Janeiro: IBGE, 2018a.

IBGE. Instituto Brasileiro de Geografia e Estatística. Panorama nacional e internacional da produção de indicadores sociais: grupos populacionais específicos e uso do tempo. Rio de Janeiro: IBGE, 2018b. 
INEP. Instituto Nacional de Estudos e Pesquisas Educacionais Anísio Teixeira. Sinopse estatística da Educação Básica 2010. Brasília, DF: Inep, 2010. Disponível em: https://bit.ly/2HIS8wP. Acesso em: 2 mar. 2019.

JANNUZZI, Paulo de Martino. Indicadores para diagnóstico, monitoramento e avaliação de programas sociais no Brasil. Revista do Serviço Público, Brasília, DF, v. 56, n. 2, p. 137-160, 2005

LOPES, Ingrid Anelise. Inclusão e direito à aprendizagem de alunos com deficiência intelectual em escola municipal paulistana. 2018. Tese (Doutorado em Educação) - Faculdade de Educação, Universidade de São Paulo, São Paulo, 2018.

MELETTI, Silvia Márcia Ferreira; BUENO, José Geraldo Silveira. 0 impacto das políticas públicas de escolarização de alunos com deficiência: uma análise dos indicadores educacionais no Brasil. Linhas Críticas, Brasília, DF, v. 17, n. 33, p. 367-383, 2011.

MELETTI, Silvia Márcia Ferreira; BUENO, José Geraldo Silveira. A escolarização de alunos com deficiência intelectual: análise dos indicadores educacionais brasileiros. In: MELETTI, Silvia Márcia Ferreira; BUENO, José Geraldo Silveira (org.). Políticas públicas, escolarização de alunos com deficiência e a pesquisa educacional. Araraquara: Junqueira \& Marin, 2013. p. 75-86.

MENDES, Enicéia Gonçalves; LOURENÇO, Gerusa Ferreira. Viés de gênero na notificação de alunos com necessidades educacionais especiais. Revista Brasileira de Educação Especial, Marília, v. 15, n. 3, p. 417-430, 2009.

MEYER, Gwen; PATTON, James M. On the nexus of race, disability, and overrepresentation: What do we know? Where do we go? On point... Brief discussions of critical issues in urban education. Washington, DC: National Institute for Urban School Improvement, 2001.

MILES, Ian. Social indicators for human development. New York: St. Martin's Press, 1985.

MONTEIRO, Agostinho dos Reis. 0 pão do direito à educação. Educação e Sociedade, Campinas, v. 24, n. 84, p. 763-789, 2003.

MUNANGA, Kabenguele. Uma abordagem conceitual das noções de raça, racismo, identidade e etnia. In: BRANDÃO, André Augusto (org.). Cadernos PENESB nº 5. Niterói: EdUFF, 2003. p. 1-17.

NICHOLSON, Linda. Interpretando o gênero. Estudos Feministas, Florianópolis, v. 8, n. 2, p. 9-41, 2000.

OLIVEIRA, Luiza Maria Borges. Cartilha do Censo 2010: pessoas com deficiência. Brasília: DF: SDH/PR: SNPD: Coordenação-Geral do Sistema de Informações sobre a Pessoa com Deficiência, 2012.

ONU. Organização das Unidas. Convenção sobre os direitos das pessoas com deficiência: aprovada pela Assembleia Geral da ONU. Genebra: ONU, 2006.

OSÓRI0, Rafael Guerreiro. 0 sistema classificatório de cor ou raça do IBGE. Brasília, DF: Ipea, 2003. 
PEREIRA, Michelle Melina Gleica Del Pino Nicolau. Deficiência, raça e gênero: análise de indicadores educacionais brasileiros. 2016. Tese (Doutorado em Educação) - Pontifícia Universidade Católica de São Paulo, São Paulo, 2016.

PRIETO, Rosângela Gavioli; SOUSA, Sandra Zákia Lian. Educação especial no município de São Paulo: acompanhamento da trajetória escolar de alunos no ensino regular. Revista Brasileira de Educação Especial, Marília, v. 12, n. 2, p. 187-202, 2006.

PRIETO, Rosângela Gavioli et al. Inclusão escolar e políticas de educação especial: direito ao ingresso, permanência e aprendizagem em escolas municipais paulistanas. São Paulo: Fapesp, 2018.

SASSAKI, Romeu Kazumi. 0 censo de pessoas com deficiência na era da inclusão. Revista Nacional de Reabilitação, São Paulo, v. 1, n. 32, p. 4-7, 2003.

SCHWARCZ, Lilia Moritz. Nem preto nem branco, muito pelo contrário: cor e raça na sociabilidade brasileira. São Paulo: Claro enigma, 2012.

SCOTT, Joan. Gênero: uma categoria útil de análise histórica. Educação e Realidade, Porto Alegre, v. 20, n. 2, p. 71-99, 1995.

VELTRONE, Aline Aparecida; MENDES, Enicéia Gonçalves. Descrição das propostas do Ministério da Educação na avaliação da deficiência intelectual. Paidéia, Ribeirão Preto, v. 21, n. 50, p. 413-421, 2011.

Recebido em: 17.12.2019

Aprovado em: 21.07.2020

Ingrid Anelise Lopes é professora de educação especial na Escola de Aplicação da Universidade de São Paulo (USP) e pedagoga no Instituto Federal de Educação, Ciểncia e Tecnologia de São Paulo (IFSP). Doutora em educação pela Faculdade de Educação da USP. É membro do Grupo de Pesquisa (CNPq) Políticas de Educação Especial.

Roseli Kubo Gonzalez é docente no curso de Pedagogia do Centro Universitário Senac. Doutora em educação pela Faculdade de Educação da USP. É membro do Grupo de Pesquisa (CNPq) Políticas de Educação Especial.

Rosângela Gavioli Prieto é docente da Faculdade de Educação da USP. Doutora em educação pela Faculdade de Educação da USP. É coordenadora do Grupo de Pesquisa (CNPq) Políticas de Educação Especial. 